\title{
Ser caballero andante en tan detestable edad: antiguos y modernos en la autoconstrucción caballeresca de Don Quijote
}

\author{
RaÚl Álvarez MORENO*
}

Omnia nova placet

\begin{abstract}
Muchos son los aspectos que resultan llamativos y extravagantes en el Quijote, pero sin duda, el hecho de que un hidalgo pobre de un lugar manchego se atreva a retar a los caballeros andantes del pasado y, como ellos, se juzgue con posibilidades de llegar a ser monarca o emperador, ha sido siempre uno de los más sugestivos. Como señala Maravall, hay conceptos fundamentales a los que podemos referir todo acontecimiento de la vida de una colectividad en un espacio y tiempo determinados (Antiguos y Modernos 2). La disputa entre antiguos y modernos es sin duda uno de ellos, y como referente ideológico que vertebra el Quijote, nos ofrecería bastantes de las claves para explicar, no sólo la singular afirmación con la que he abierto este artículo, sino la propia obra en sí, entendida como autoconstrucción y deconstrucción de un personaje. De esta manera, el referido eje de pensamiento se puede observar en una triple dicotomía a lo largo de la obra, hasta llegar a Don Quijote: Armas vs. Letras; dentro de las Armas, Caballeros Andantes vs. Caballeros Cortesanos; y dentro de los Caballeros Andantes, Caballeros Andantes del Pasado vs. Don Quijote, en el individualismo representado por su experiencia personal ${ }^{1}$.
\end{abstract}

* Michigan State University.

1. Según MONER la controversia entre las Armas y las Letras traspasaría toda la obra, constituyéndose en su eje principal (95). Sin afirmar que esta oposición quede en algún momento neutralizada, pensamos que la armonización de este debate, que persiste también a lo largo de la obra y que encarnaría el propio Don Quijote en palabras de este mismo crítico (106), convierte a las otras dos últimas oposiciones en los verdaderos componentes dialécticos de la obra. 
La querella entre antiguos y modernos, que tuvo un origen literario, estaría relacionada con la renovación y la sucesión, y pronto se hizo extensible a otros campos del obrar y del saber del hombre (Curtius 251). Entre estos estaría el de la guerra, como ejemplifica el propio Cervantes, que aprovecha toda ocasión para señalar que participó en la "más alta ocasión que vieron los siglos" (Cervantes 573); y más específicamente el de la caballería, que es la que ordena la forma de ver y entender el mundo de nuestro protagonista. Será el punto de vista de éste el que adoptemos durante todo el trabajo, al menos que se señale lo contrario, pues nos interesa resaltar su propia evolución al respecto, especialmente en el contraste entre la realidad de la novela y el discurso ante el que se construye a sí mismo, basado en la emulación y superación de los antiguos caballeros andantes de los textos ${ }^{2}$. En relación esto, se podría objetar que frente a la Primera Parte, donde está más claro, en la Segunda entran en juego otras motivaciones generadoras de acción, como tener hazañas que dar a la imprenta, o la necesidad de afirmarse ante el yo apócrifo de Avellaneda. Podemos admitirlas, si bien puntualizando, que nunca desaparecerá la superación de sus modelos como motor principal del personaje.

Las siguientes páginas, intentarán analizar las claves de ese proceso de autoconstrucción de Don Quijote como caballero andante, mostrando cómo la conciencia de su imposibilidad le conduce al desencanto, y cómo, paradójicamente, logra al final el triunfo sobre Amadís y sus seguidores. Para ello, empezaré estudiando el mismo fenómeno de la imitatio como superación, partiendo de la toma de las armas frente a las letras por parte de Don Quijote, con dos objetivos fundamentales para su ejercicio. A continuación, me detendré en la doble estrategia seguida por el personaje para lograr su fin: cuestionamiento de los antiguos y automagnificación ensalzadora en relación con sus principales atributos. Continuaré mostrando, siempre desde su yo subjetivo, los problemas ofrecidos por su actualidad en la conclusión de sus propósitos, así como los procedentes de sus propias carencias y de los fallos en el mismo proceso de emulación, y que le conducen al fracaso. Finalmente, el artículo se cerrará, definiendo lo aparente de esa derrota en relación con el significado de su muerte.

Entre los conceptos de más trascendencia heredados de las culturas clásicas, sin duda la imitatio tuvo un lugar primordial, con su concepción del saber y la historia paradigmática respecto a la autoridad de los antiguos, y con un estrecho vínculo a la idea de progreso. Observamos este concepto en el Quijote a todos los niveles: el pastoril, con un Grisóstomo que fracasa tratando de imitar e imponer un modelo arcádico a Marcela; el religioso, con Zoraida, cuyo marianismo tiene que ver más con la emulación de un modelo revelado que con un conocimiento del cristianismo; o el literario, como veremos en casa de don Diego de Miranda a propósito de la poesía, cuando

2. Pensamos que en esta línea va FoucAult cuando afirma que para Don Quijote lo importante no es transformar la realidad real sino la del signo, calificando su aventura como un desciframiento del mismo. Don Quijote, según el autor francés, leería el mundo para demostrar los signos (54). 
Don Quijote, como moderno, reconviene a don Lorenzo por no estimar la creación nueva en romance frente a los clásicos: "Y a lo que decís, señor, que vuestro hijo no estima mucho la poesía de romance, doyme a entender que no anda muy acertado en ello." (Cervantes 695). Como ejemplifican muy bien estas palabras de nuestro caballero, este eje significativo, presente en la Edad Media, trajo con el Renacimiento el que el Imitator se constituyese en un Aemulator, o alguien que yendo más allá de la mera imitación buscaba una suerte de superación en sus modelos. El concepto así concebido, se acabó proyectando desde lo artístico a la guerra, por la influencia de la dicotomía del Discurso de las Armas y las Letras, de vital importancia en la obra que nos ocupa, y cuya mera oposición reflejaba la afinidad que hacía posible el vínculo. De acuerdo con Russell, la subdivisión de las letras se proyecta sobre las armas en la España del siglo XV, cuando la teoría medieval de una sociedad dividida en estamentos inmutables cae (221). Una clara muestra de esta ligadura entre el discurso de las Letras y el de las Armas, con la trasversal influencia de la imitatio, lo encontramos en el mismo protagonista, cuando tentado por las letras, sigue guardando siempre la relación imitativa con sus modelos, en este caso Belianís:"Pero, con todo, alababa en su autor aquel acabar su libro con la promesa de aquella inacabable aventura, y muchas veces le vino el deseo de tomar la pluma, y dalle fin al pie de la letra, como allí promete; y sin duda lo hiciera, y aún saliera con ello, si otros mayores y continuos pensamientos no se lo estorbaran"(35). Afortunadamente, Don Quijote se decidió finalmente por imitar a los personajes en lugar de a los autores de los libros ${ }^{3}$. Por otro lado, la emulación de los modelos era algo consustancial al género que Cervantes intentaba parodiar, siendo presentadas las novelas de caballería en sus prólogos como buenos ejemplos a seguir, con unos personajes beneficiosos a la sociedad, con lo que se convertían en modelo tanto literario como vital "the model of a virtuous knight, who never acted out of self-interest" (Eisenberg 45). En función de la señalada afinidad, los parámetros aplicables a las letras por el Renacimiento lo van a ser también a las armas, como el antagonismo entre los antiguos y los modernos, y el afán superador de los segundos. Lo observamos en el prólogo del Amadís, donde Montalvo hace sobresalir a los combatientes de la guerra de Granada por encima de los antiguos atenienses (Rodríguez de Montalvo 220). Y ya en nuestra obra, está presente desde los sonetos introductorios, que a pesar de su tono paródico no dejan lugar a dudas, pues el hecho de burlarse de algo es prueba de su existencia. De este modo, tenemos a Belianís de Grecia envidiando las proezas de Don Quijote, a Oriana anhelando el haber sido tratada por Amadís con el mismo comedimiento que Dulcinea, a Galandín, escudero de Amadís, envidiando a Sancho

3. Encontramos desde el principio en Don Quijote, la voluntad de ser ficción que superase a la ficción que le servía de modelo. Antes de empezar sus aventuras, ya se piensa personaje literario, incluso nos da el principio de su novela, lo que potenciaría su imagen como escritor de novelas de caballería, ofreciendo incluso la insólita posibilidad de un caballero escribiendo su propia novela, en un posible e interesante caso de autobiografismo ficcional. (CERVANTES 41). 
y a sus alforjas llenas de comida, al Caballero de Febo afirmando que su espada nunca igualó a la de nuestro hidalgo, e incluso a Orlando Furioso, que aunque loco también, nunca pudo ser el igual de nuestro Don Quijote en su locura. Todas estas ideas, como veremos, aparecerán desarrolladas en el libro, y por si hubiese alguna duda serán expresadas por nuestro hidalgo de forma directa: "Yo soy, digo otra vez, quien ha de resucitar los de la Tabla Redonda, los Doce de Francia y los Nueve de la Fama, y el que ha de poner en olvido los Platires, los Tablantes, Olivantes y Tirantes, los Febos y Belianises, con toda la caterva de los famosos caballeros andantes del pasado tiempo, haciendo en este en que me hallo tales grandezas, estrañezas y fechos de armas, que escurezcan las más claras que ellos ficieron." (Cervantes 194); o indirecta, como cuando coge un romance donde se cuenta un hecho nunca superado de un caballero, Lanzarote, y se pone él en su lugar, suplantación que muestra de forma diáfana sus intenciones:

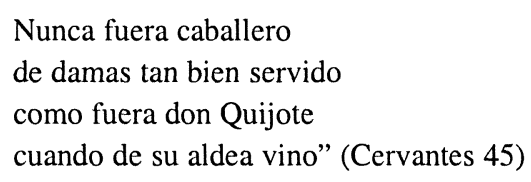

No obstante, la creencia de Don Quijote de excepcionalidad frente a sus modelos, si bien es un proceso que nace en él mismo, no debemos olvidar que es continuamente alimentado desde fuera por los que intentan "curarle". Los elogios y alabanzas de los mismos contribuyen a su construcción también, por ejemplo Dorotea en la forma de Micomicona (Cervantes 318), el Bachiller Carrasco en la Segunda Parte "Si por buena fama y si por buen nombre va, solo vuestra merced lleva la palma a todos los caballeros andantes" (Cervantes 598), o el propio Merlín con su profecía en la Cueva de Montesinos, lo que podría ayudarle a desencantar a los allí encantados (Cervantes 755).

Una vez expuesta la construcción mental que lleva a Don Quijote a cimentarse en la preeminencia sobre sus prototipos, conviene desvelar las motivaciones que le llevan a tal fin, y que tendrían relación con idea de la fama, y con la renovación moral de la realidad sobre la que actúa. Ganar gloria, fama más allá de la muerte era otro de los vínculos entre los hombres de letras y los de armas (Lida de Markiel 118). Con el Renacimiento, esta cualidad se enlaza estrechamente a la superación de los modelos antiguos, tomados del pasado, pero proyectados hacia el futuro en uno mismo, haciendo pervivir los logros personales tras la muerte con el objeto de ser recordado. Esta es la razón que lleva a Don Quijote a valorar positivamente a los caballeros del pasado, pues finalmente estaría invirtiendo en la creación de unos hábitos que redundarían en la futura valoración de si mismo ${ }^{4}$. Así, su intención última, tras

4. En esta línea podemos interpretar sus enfados cuando se niega la existencia de sus modelos, o sus reticencias ante el Caballero del Verde Gabán, cuando éste le señala que su historia pondrá en olvido la de los fingidos caballeros andantes anteriores (691). 
desbancar a sus modelos, sería ponerse él como ejemplo para los caballeros andantes del futuro:

Caballero andante soy, y no de aquellos de cuyos nombres jamás la Fama se acordó para eternizarlos en su memoria, sino de aquellos que, a despecho y pesar de la mesma envidia, y de cuantos magos crió Persia, bracmanes la India, ginosofistas la Etiopía, ha de poner su nombre en el templo de la inmortalidad para que sirva de ejemplo y dechado en los venideros siglos, donde los caballeros andantes vean los pasos que han de seguir, si quisieren llegar a la cumbre y alteza honrosa de las armas.(Cervantes 515 )

Esta pretensión de gloria, acabará siendo modificada, como señalamos, en la Segunda Parte, donde el saberse publicado someterá a Don Quijote a una autovigilancia de su conducta que influirá en sus hazañas, pero cuyo análisis rebasa los límites de este artículo. Sí conviene detenernos en el otro gran motivo que conforma el intento superador de nuestro caballero, y que le integra totalmente en los modernos como portador de ideas de progreso. Según los ideales humanistas, la virtud era una parte integral de la fama, siendo sin ella mera publicidad o mala fama (Riley 28). Sin embargo, Don Quijote irá mucho más lejos y, paradójicamente, no sólo no es la antigüedad, el pasado anacrónico que representarían los libros de caballería, sino que representa en la idea de futuro, al hombre nuevo del Renacimiento que tenía la necesidad de diferenciarse de los del pasado. Pero además, el mismo humanismo fijaba unos estándares más altos para nuestro caballero, poniendo en sus armas la responsabilidad moral de cambiar las circunstancias que le rodeaban, de rehacer el mundo en torno a él desde una realidad detestada, superando con ello en responsabilidad a sus modelos, mucho menos sociales, como señala Maravall: "Armas y su ejercicio toman un nuevo sentido moral en el pensamiento de la época que no tenían para los antiguos caballeros" (El Humanismo de las Armas 124). El mismo proceso de Construcción-Desconstrucción al que nos venimos refiriendo ha sido interpretado por este eminente crítico en términos de Utopía-Contrautopía de la situación político-social de la España de Cervantes, en la revisión que hace de sus ideas anteriores (Maravall, Utopía y Contrautopía $)^{5}$. El afán de convertir a Cervantes en un reformista a la vanguardia de su tiempo, le habría llevado a ver como motores de Don Quijote, en lugar de la imitación de unos modelos caballerescos, la primacía del concepto de selección por mérito individual típico de la burguesía, y un concepto ascético depurador orientado hacia la virtud (Maravall, Utopía y Contrautopía 89 y 97). Sin rechazar el gran peso que estas ideas tienen en la obra, nosotros defenderemos la compatibilidad de ambas con la emulación de los referidos

5. Maravall vería en la derrota de Don Quijote la imposibilidad de un ideal, cuestionando no la utopía que busca una reforma real y eficaz, sino la sustitución que se había hecho de ésta por una evasión inoperante en la época en la que surgió la novela (MARAVALL, Utopía y Contrautopía 122). 
modelos caballerescos, haciendo a los argumentos del crítico algunas puntualizaciones. En primer lugar, debemos recordar que Don Quijote nunca olvida la inferioridad de su origen, y la completa significación del episodio de los leones, como veremos, va en ese sentido ${ }^{6}$. Lo mismo podemos decir de la apreciación de Dulcinea, a la que considera de alta sangre hasta que él mismo desvela quién es en realidad y el discurso de la nobleza de nacimiento se hace insostenible ante su principal interlocutor, Sancho. Además, la propuesta de que actúa exclusivamente dentro del proceso de conquista de unos valores morales, no es ajena a la mayoría de sus modelos, aunque se intensifique en Don Quijote por influencia del humanismo renacentista, lo que le hace también superior a los demás caballeros del pasado. Además, Don Quijote piensa que posee estos valores desde el principio, por el mero hecho de ser caballero andante, sin olvidar el incentivo ya comentado de la fama. Pero llegado el caso, el aspecto que vamos desgranando no resulta tan decisivo, excepto en lo que respecta a su función como elemento de superioridad ante sus modelos. De hecho, en su percepción subjetiva de la realidad no será relevante para nuestro caballero si estos ideales son consecuencia del paso del renacimiento o no, sino el que él se los atribuya a los caballeros andantes a los que emula ${ }^{7}$. En realidad, la interpretación que el insigne crítico propone no es excluyente ni incompatible con la que nosotros proponemos, pues en cualquier caso, interpretemos en los términos que lo hagamos la construcción de Don Quijote, sus modelos primarios no dejan de ser los caballeros antiguos, aunque estos se vean impregnados, como es lógico, por las nuevas ideas del humanismo utópico renacentista.

Si bien, como queda dicho, la propia misión de Don Quijote, por ser menos individualista, le hace superior frente a lo imitado, nuestro hidalgo ejercerá también su anhelo de superación con una doble estrategia que merece ser comentada. De este modo, y en consonancia con la actitud humanista de criticar a los antiguos, o al menos de no aceptarlos sin ser cuestionados, Don Quijote presenta también a sus modelos como imperfectos o insuficientes, en otro discurso más sutil, aunque paralelo, al de la alabanza de los mismos. Así, cuando pone a los dos ejemplos que piensa seguir en Sierra Morena para su penitencia, Orlando y Amadís, y Sancho le señala que ellos tuvieron causas para ella, la reacción del caballero será la de afirmar su superioridad, pues si

6. De hecho, Don Quijote nunca renunciará a su pretendida alcurnia, dejando al futuro sabio que escriba la historia la misión de emparentarle con la realeza.

7. Otros aspectos en los que apoya su tesis MARAVALL deben tomarse con cuidado. Así, la consideración del viaje como motivo de perfeccionamiento, es verdad que tiene un gran componente renacentista, pero también es cierto que este componente ya existía en las peregrinaciones medievales. Incluso el cambio de nombre de Don Quijote es dudoso que tenga más relación con el intento del mismo de dejar constancia pública de su renovación en pos de la virtud humanista que con la literatura caballeresca, como se sugiere (Utopía y Contrautopía 142). Además, su interpretación omitiría otros fenómenos que, como veremos, influirían en su fracaso además de las circunstancias socio-históricas adversas, como las propias limitaciones personales del caballero o los defectos en la imitación de sus modelos. 
piensa igualarlos en sus hechos, piensa superarlos en las circunstancias -más difíciles por no tener como Amadís rosario ni ermitaño-, y en las razones, que no existen: "El toque está desatinar sin ocasión y dar a entender a mi dama que, si en seco hago esto, ¿qué hiciera en mojado?” (Cervantes 259). En relación con los encantadores, dejará claro que a los otros caballeros les ayudaron para completar sus hazañas, mientras que a él sólo le persiguen (Cervantes 129). En adición, y a pesar de sus constantes tropiezos, los caballeros del pasado sufrieron mayores afrentas que él, como el Caballero de Febo con cierta trampa que se le hundió debajo de los pies en un castillo, apareciendo en una honda sima debajo de tierra, atado de pies y manos (Cervantes 151). Por otro lado, su conocimiento de las reglas de caballería fue menor que el suyo, como consecuencia de sus copiosas e insuperables lecturas: "Y entiende con todos tus cinco sentidos que todo cuanto yo he hecho, hago e hiciere, va muy puesto en razón y muy conforme a las reglas de caballería, que las sé mejor que cuantos caballeros las profesaron en el mundo" (256). El propio Amadís, el modelo de los caballeros andantes, no fue como le pintaron sino que lo hicieron como había de ser, para dar ejemplo a los hombres venideros de sus virtudes, con lo que indirectamente le está rebajando frente a él (Cervantes 257). La fama de los caballeros antiguos es, por otra parte, menor, pues no estuvieron en la estampa mientras ocurrían sus aventuras, no fueron clásicos en vida como él (Cervantes 690). Este ensalzar sus cualidades apuntando a las carencias de los otros, llegará al máximo con Roldán, al que cuestiona abiertamente: "Si Roldán fue tan buen caballero y tan valiente como todos dicen, ¿qué maravilla, pues, al fin era encantado, y no le podía matar nadie si no era metiéndole un alfiler de a blanca por la punta del pie, y él traía siempre los zapatos con siete suelas de hierro?" (Cervantes 272). Otro recurso que es usado para cuestionar a los caballeros antiguos, la igualación de éstos con los caballeros cortesanos de su presente, ha llamado la atención de Moner (108), en lo que supondría un salto en los niveles dicotómicos señalados con anterioridad. Según el hispanista francés, el episodio de la Cueva de Montesinos manifestaría la superación de los modelos quijotescos, ejemplificados en la figura de Montesinos, paladín heroico del ciclo carolingio, que habría trocado la espada por un rosario, quedando igualado en su inacción e inmovilidad a los caballeros cortesanos del presente de Don Quijote. Esta apreciación, que según Moner (118) criticaría la clericalización de la sociedad española, se haría extensible a Gaiferos, presentado al menos inicialmente en el retablo de Maese Pedro, también como ocioso y descuidado, de acuerdo con la imagen de un conocido romance anónimo de finales del siglo XVI, y que contrastaría con la prestancia e impulsividad de nuestro protagonista en el episodio.

Por otra parte, esta estrategia de rebajamiento de los rivales hacia los que se orienta su imitatio, tendría su contrapartida en la automagnificación ensalzadora de Don Quijote, para la que usa sus principales accesorios caballerescos: caballo, escudero y dama. En consecuencia, encuentra a Rocinante tan digno que "ni el Bucéfalo de Alejandro ni Babieca el del Cid con él se igualaban" (Cervantes 37), por lo que a pesar de los problemas que le acarrea 
durante toda la obra, e incluso ser el causante directo de su derrota, siempre se resistirá a reemplazarlo. Con Sancho, ocurre otro tanto, pues piensa superar a todos los caballeros en la liberalidad mostrada con él, haciéndole gobernador o incluso rey, y además sin esperar a que sea viejo, frente a lo que los otros caballeros habían hecho antes (Cervantes 87). En cuanto a amores, Don Quijote es inigualable en cantidad: "!Qué tengo de ser tan desdichado andante, que no ha de haber doncella que me mire que de mí no se enamore...!" (Cervantes 915), pero sobre todo en calidad, por el hecho de no haber tocado nunca a otra mujer, el que sus amores se reduzcan al sentido más noble de la vista, "a un honesto mirar", y que pertenezcan al más prestigioso género de los platónicos continentes (Cervantes 265). Es probablemente desde su amor a Dulcinea, desde donde más superior se piensa al resto de los caballeros, por supuesto ante el más frívolo Galaor, pero también ante el caballero de los caballeros, Amadís, cuya dama Oriana fue hecha dueña, dando a luz a Esplandián. De acuerdo con Maravall, esta virtud y castidad extremas serían una forma de ser mejor, en línea con el ideal moral del hombre reformado del Renacimiento ya expuesto. (El Humanismo de las Armas 112).

Si como hasta el momento hemos visto, Don Quijote se construye frente a los antiguos con un objetivo más noble que supera el individualista de la fama, y recurre en esta construcción a diferentes maniobras para articular un discurso de superioridad que mine la propia alabanza de sus modelos, nuestro caballero chocará con diferentes problemas en la consecución de su proyecto. Éstos se derivarán, principalmente, del mismo tiempo que le toca vivir, y de sus personales carencias y errores al imitarlos. Subjetivamente, Don Quijote concibe la historia como un proceso continuo y diferenciado de épocas, básico para que puedan compararse unas con otras (Maravall, Antiguos y Modernos 216). En relación con esto, tendríamos su famoso discurso evocador de la Edad de Oro ante los cabreros, donde el contraste entre el entonces y el ahora, daría sentido a la caballería andante. Pero la línea discursiva de nuestro protagonista no es una mera comparación entre los tiempos en que Saturno gobernó el Lacio y su momento actual, como se ha dicho, sino que entran en juego tres tiempos: el mítico de la Edad de Oro que hay que rescatar, el indefinido de los caballeros andantes en el que el protagonista no hace diferencias, y que incluiría a los caballeros reales del siglo anterior como Suero de Quiñones 8 , y el del siglo XVI que le toca vivir (Cervantes 586). Esta circunstancia enriquecería sustancialmente su función en la historia, pues a la de restituidor de la Edad de Oro como sus modelos, habría que añadir otra más trascendente relacionada con el sentido ético ya expresado: la de garantizar el progreso como superación de lo antiguo para que la historia avance a mejor, constituyéndose en el eslabón

8. Los libros de caballerias en su indeterminación histórica siguen el tópico medieval del florebat olim, que sirve para ambientar a un personaje ejemplar alejado del presente pero sin incustrarlo en un momento concreto, pudiendo resultar irremisiblemente cortado en un ayer sin continuidad (Maravall. Antiguos y Modernos 202). Los caballeros andantes reales del Siglo XV han sido estudiados por la obra de Martín de RIQUER incluida en la bibliografía. 
que salva a su siglo del estancamiento o decadencia moral. En función con esta idea, el momento vivido por Don Quijote va a ser interiormente percibido como detestable y corrupto, en contraposición con la caballería andante no cortesana, mejorada en él. Esta circunstancia, que hará más valiosa y arriesgada su misión que la de Amadís y sus seguidores, estaría relacionada con la idea moderna de la contemporaneidad, concebida siempre como la etapa más problemática de la historia, con el objeto de desviar la atención hacia el presente. Así, Don Quijote necesita un mundo peor que el pasado para construirse a si mismo como mejor frente a los modelos antiguos a los que imita, y lo erige, paradójicamente, con las circunstancias que han hecho desaparecer a la caballería andante en el siglo anterior. Esta edad mala, como dirá Don Quijote, porque la verdad no llega a los oídos de los príncipes (Cervantes 593), todavía conserva restos de la época mítica que se pretende restaurar, como los cabreros, que le agasajan sin pedir nada a cambio, aunque los nuevos tiempos, por lo general, traen nuevas situaciones que lo descolocan y lo convierten en un anacronismo?.

Primeramente, Don Quijote tendrá que enfrentarse con una realidad precapitalista mucho más dura que los caballeros anteriores, donde todo se compra y se vende, lo que pone muchas trabas a su labor. Como caballero andante de los nuevos tiempos, necesitará llevar dinero para pagar su hospedaje, su escudero le requerirá salario, e incluso Dulcinea le hará una petición pecuniaria en la Cueva de Montesinos ${ }^{10}$. Además, nuestro héroe afrontará la falta de veracidad consustancial a un siglo, donde la mentira se enseñorea, y donde la palabra no es cumplida ni por los vencidos, como por ejemplo en el caso de Juan Haldudo, azotador de Andrés, lo que causará numerosos menoscabos a sus hazañas. También, frente a sus modelos, que funcionaban en un mundo en el que estaban por encima de la ley, sus aventuras le ponen desde el principio, fuera de ésta ${ }^{11}$. La legalidad constituida, representada por la Santa Hermandad, llega ahora hasta los sitios más recónditos, y el nuevo estado moderno posee mecanismos de control más eficaces que en la Edad Media: "El Estado pretende que no haya más poder que el suyo, ni más ley ni más justicia que las suyas. Imprime una homogeneidad en la obediencia a todos y elimina privilegios y exenciones y prohíbe toda acción particular en el orden de sus funciones" (Maravall, El Humanismo de las Armas 42). Por si fuera poco, los encantos de los magos de estos nuevos tiempos, como ser llevado en un carro con bueyes, son insólitos y más difíciles de sufrir por el caballero, sin que Don

9. Don Quijote será siempre consciente de la mayor dureza de su siglo para el ejercicio de las armas, sabiendo que a pesar de su fuerte brazo, no las tiene todas consigo: "Que aún no sé cómo prueba en estos tan calamitosos tiempos nuestros la caballería, y no querría que por pocas cosas penase mi alma en el otro mundo" (CERVANTES 207)

10. Para un comentario de este incidente, interpretado como degradación del mito amoroso en contacto con la realidad, ver MONER (52-59).

11. No olvidemos que sobre Don Quijote, tras la aventura de los galeotes, recaerá un auto de prisión por salteador de caminos. 
Quijote encuentre referentes en sus lecturas: "Pero quizá la caballería y los encantos de estos nuestros tiempos deben de seguir otro camino que siguieron los antiguos. Y también podría ser que, como yo soy nuevo caballero en el mundo, y el primero que ha resucitado el ya olvidado ejercicio de la caballería aventurera, también nuevamente se hayan inventado otros géneros de encantamientos y otros modos de llevar a los encantados 12 " (Cervantes 510). Son estos encantamientos nuevos, proyectados sobre todo en Dulcinea, los que abrirán una grieta insuperable entre él y sus modelos, pues al tomar venganza de él en su dama, atacan a la base misma de su caballería, y de forma que no puede combatirlos directamente. Esta es la razón, por la que tras vencer al caballero de los Espejos, recapitulará muy consciente de su situación: "Finalmente, decía entre sí que si él hallara arte, modo o manera como desencantar a la señora Dulcinea, no invidiara a la mayor ventura que alcanzó o pudo alcanzar el más venturoso caballero andante de los pasados siglos" (Cervantes 687). Tampoco hemos de olvidar su constante preocupación por el encantador que escriba su historia, generalmente visto de forma negativa, lo que inquieta siempre a Don Quijote, sabedor de que su fama dependerá en igual medida de quién y cómo se cuente la historia, que de sus hazañas objetivas, lo que explica, junto con los motivos de Cervantes como autor, su obsesión final con el apócrifo de Avellaneda. Otro aspecto relevante de los nuevos tiempos que habrá de afrontar, será el hecho de que el estándar para medir a un caballero haya cambiado, pareciendo mejor en su tiempo el caballero cortesano de vida ociosa que conoce las armas por teoría, que el caballero andante que las practica. Esta percepción subjetiva de Don Quijote tiene una base real, pues la nobleza de finales de la Edad Media, cuando los caballeros andantes reales florecieron en España, tenía un sistema de valores diferente de la nobleza del siglo en que vive nuestro hidalgo, mucho más alejada de los ideales guerreros de la Reconquista. Esto explicaría el disgusto de Don Quijote en el palacio de los duques, ya que éstos con su vida ociosa y regalada le alejan de sus modelos. Incluso la degeneración de estos nobles y su aplebeyamiento tendrán consecuencias directas en el rebajamiento objetivo en el ejercicio de las armas de nuestro héroe. $\mathrm{El}$ hecho de que los duques dependan económicamente de un villano rico, hará que Don Quijote tenga que retar al que cree su hijo, protegido por los duques, renunciando para ello a su hidalguía y con el consiguiente menoscabo hacia el gran caballero que aspira a ser (Cervantes 978). En general, la vida de los caballeros andantes está siempre sometida a peligros y desventuras, pero si unimos a los lugares frecuentados por Don Quijote para sus hazañas, un mundo donde estamentos sociales y grupos genéricos no están tan definidos como en las novelas de caballería, el héroe tendrá que encarar constantemente situaciones que supongan una disminución con respecto a sus modelos. Entre estas estarían el tener que tomar las armas contra villanos,

12. Estos referentes existen en Chrétien de Troyes, como bien indica Martín de RiQuer en nota, pero a nuestros efectos lo importante no es la realidad sino lo que nuestro caballero cree. 
como las libertades verbales y la rebelión de su escudero, que incluso le pone la pierna en el pecho, o la tesitura de ser agredido físicamente por mujeres, que ya no serán las meras espectadoras de las novelas de caballerías, sino que participarán de forma más decisiva e incluso violenta en la acción.

Otros nuevos cambios sociales, que vendrían a complicar aún más los deseos de Don Quijote de sobrepasar a los antiguos, estarían relacionados con las nuevas formas de hacer la guerra, y en concreto con el uso de las armas de fuego. Don Quijote tiene miedo de que una bala trunque su camino hacia la fama, calificando la edad en que le toca ejercer las armas de detestable por este motivo, y añorando un pasado en que no existían (Cervantes 423). La amenaza estará siempre presente, y no la deja pasar por alto el narrador en el episodio de los galeotes, donde tras dar Don Quijote la primera lanzada a un cuadrillero, comenta su acierto, al ser el que llevaba escopeta (Cervantes 229). O en el episodio de los del rebuzno, ante los que Don Quijote ha de volver la rienda a Rocinante en perjuicio de su valor, por ir armados con arcabuces (Cervantes 794). Pero si bien la presencia de estos ingenios, suponía de algún modo un duro golpe a Don Quijote, por ponerle en tesituras que menoscaban su prestigio para salvar su vida, paradójicamente le hacían superior a sus modelos por los mayores riesgos implícitos en el ejercicio de las armas. Esto conectaría con la polémica sobre las armas de fuego surgida en el Renacimiento, sobre quiénes eran superiores en la guerra, los antiguos o los modernos ${ }^{13}$. A finales del siglo XVI y principios del XVII, fecha de composición de la obra que nos ocupa, el estado de la cuestión era más favorable a la mayor virtud de los combatientes modernos, ya que el mayor poder destructor de las armas empleadas, hacía necesario un mayor arrojo en aquellos que se exponían a su acción. Tampoco hay que olvidar a propósito de las armas, que algo tan importante para un caballero como los duelos, había sido prohibido en el Concilio de Trento (1545), como bien le recuerda el duque a Don Quijote, lo que limitaba para el moderno caballero andante las posibilidades que este ejercicio ofrecía para alcanzar la gloria. Incluso, la propia posibilidad de alcanzar ésta mediante acción movida por el ideal caballeresco, había sido condenada por la Inquisición, prohibición que bloqueaba uno de los ya comentados motores de Don Quijote en su superación de los antiguos, al sancionarlo la Iglesia de su siglo (Lida de Markiel 118) ${ }^{14}$. Ante estas circunstancias tan desfavorables para la caballería, no es extraño que un bandido como Roque Guinart se constituya en el verdadero paradigma de hombre acción de su tiempo, que le busquen las damas con problemas como Claudia Jerónima, que a sus hombres se les llame "escuderos", y que el propio Don Quijote se le ofrezca como

13. Esta polémica en la que participaron figuras como Maquiavelo, Herrera, Salas Barbadillo, o el propio Gracián, es recogida de forma detallada por Maravall en El Humanismo de las Armas de Don Quijote (162), en Utopía y Contrautopía en el Quijote (134), y en Antiguos y Modernos (545).

14. En relación con esto no hemos de olvidar que Don Quijote es excomulgado por uno de los frailes a los que ataca en el capítulo XIX de la Primera Parte, por lo que en cualquier caso estaba fuera de los márgenes de la Iglesia de su tiempo. 
modelo para que tome la caballería andante, rebajándose a si mismo al rebajar la categoría de su discípulo. Además, y en tanto y en cuanto, las circunstancias arriba expresadas van haciendo imposible la utopía de superación de sus modelos, el deseo de Don Quijote por haber nacido en época más favorable se irá acrecentando. Así, ya de vuelta a casa tras su derrota, al ver unos tapices sobre Helena y Dido en un mesón no podrá evitar remarcarlo con amargura: "Estas dos señoras fueron desdichadísimas, por no haber nacido en esta edad, y yo sobre todos desdichado en no haber nacido en la suya" (Cervantes 1120 ).

Pero no todas las dificultades y contratiempos, que le distancian de sobrepujar a sus ideales, son concebidos por Don Quijote como algo inherente a su siglo. Sus propias carencias e incluso los errores en la imitación de sus modelos, también jugarán un papel capital, si bien será menos consciente de ellos, o pretenderá intencionalmente no serlo, evitando así el enfrentarse con la realidad o proyectando estas razones hacia los aspectos externos que acabamos de comentar. Las deficiencias personales de nuestro protagonista van a llevar su discurso a explicaciones continuas ante sus interlocutores, que muestran la falta de viabilidad de su proyecto. Entre estas destacaría su nacimiento, la falta de calidad social para ejercer la caballería andante, lo que se constituye en un gran complejo de su emulación, acentuado por el hecho de saberse no criado, como sus paradigmas, en la corte de un rey. Esta circunstancia, además de someterle a patéticas justificaciones, le convertirán en un defensor a ultranza de la movilidad social, uno de los leiv-motiv de la obra ya comentados, destacando entre los linajes que se dan en el mundo, el de los que tuvieron su origen en gente baja y fueron subiendo hasta llegar a ser grandes señores mediante sus obras (Cervantes 217). De este modo, confía en que el sabio que escriba su historia encontrará una parentela que le empariente con reyes, y sólo desde este complejo tendría completa explicación el episodio de los leones, pues si bien es cierto que podemos interpretar que actúa ante don Diego de Miranda e incluso ante sus futuros lectores, Don Quijote conoce por sus lecturas los vínculos entre la realeza y estos animales, que respetaban instintivamente a los que tenían sangre real (Eisenberg 60). Esta limitación se haría extensible a su dama, Dulcinea, a la que habrá de defender ante los duques con el mismo argumento, como hija de sus obras (Cervantes 829). Por otro lado, frente a los caballeros antiguos, se sabe pobre, viejo y débil, como su sobrina le señala y él reconoce antes de su tercera salida, aunque desviando las objeciones al tema de los linajes ya comentado: "Tienes mucha razón, sobrina, en lo que dices, y cosas te pudiera yo decir cerca de los linajes, que te admiraran; pero por no mezclar lo divino con lo humano, no las digo" (Cervantes 620). La conciencia de su pobreza llegará a su punto simbólico más álgido, por contraste, en el castillo de los duques, donde unos puntos que se le sueltan de una media confirmarán dolorosamente las palabras de su sobrina (Cervantes 911). Tampoco es hermoso como los caballeros a los que se propone aventajar, y su mal aspecto físico y catadura le hacen incluso ser confundido con un ventero por los caballeros que vienen en busca de don Luis en la Segunda Parte, provocando su ira: 
"¿Paréceos, caballeros, que tengo yo talle de ventero? -respondió D.Quijote-" (Cervantes 482). Este inevitable contratiempo, llevará al caballero a esgrimir la hermosura del alma frente a la del cuerpo, ante la falta de sentido que para Sancho supone el que las mujeres se enamoren de él (Cervantes 1020). Además, posee un déficit remarcable de experiencia vital, pues no ha salido de su aldea y su conocimiento es eminentemente libresco. De esta forma, será en Barcelona donde verá por primera vez el mar, contribuyendo esta inexperiencia a su omisión en el episodio de las galeras, al ser totalmente nulo en un medio que para él se sale de las estrecheces de lo conocido. Estas restricciones en su formación como caballero andante no viajado, amén de las del ámbito sobre el que discurren sus aventuras, le privarán de la superioridad moral procedente del trato con diferentes poblaciones, lo que le hubiese permitido, como a sus modelos, comparar y elegir mejor a sus enemigos ${ }^{15}$. En adición a las carencias que acabamos de expresar, se uniría la imposibilidad reiterada de no controlar la cólera: "Ahora te disculpo-dijo Don Quijote-, y perdóname el enojo que te he dado; que los primeros movimientos no son en manos de los hombres" (Cervantes 332). Don Quijote sabe perfectamente que la mesura en sus reacciones es una de las cualidades que ha de imitar y superar en los antiguos, pues el no controlarla le puede hacer temerario en lugar de valiente, además de entrar en luchas superfluas que nada añaden a su prestigio, como bien recoge Eisenberg a propósito de los caballeros andantes antiguos: "His mesura and cool temper were important virtues, for one with a hot temper too easily gets into unneceessary fights" (64).

Otro aspecto que, como antes señalamos, profundiza la separación abierta entre nuestro particular aemulator y sus moldes, son los errores cometidos en el propio proceso de imitación. Dejando aparte el hecho, desconocido o no admitido, de que se está comparando con algo sin existencia real para la muchos de sus interlocutores, Don Quijote no se explica el mundo en función de los libros de caballería, como pudiera parecer, sino que lo hace en función de sus propias necesidades psicológicas, por lo que repetidamente tenemos la sensación de que imita sólo lo que le conviene. "Su memoria es selectiva, y de cuanto lleva leído, elige lo que más a molde le cuadra, según la ocasión y el caso" (Egido 13). Además, el propio concepto humanista de la imitatio llevaba implícita la actitud de imitar los modelos para superarlos, pero actualizándolos en el presente. De haber actualizado sus modelos en lugar de reiterarlos, de haber hecho lo que los caballeros andantes pero no cómo ellos, sus posibilidades de triunfo hubiesen aumentado considerablemente. Por otra parte, Don Quijote imita mal, sin tomar el modelo que más se adecua a su naturaleza. Como acabamos de ver es de temperamento colérico, pero imita a Amadís, que él mismo describe como "tardo en airarse y presto en deponer la ira" (Cervantes 588).

15. Aunque España era un territorio muy variado, su localismo no coincidía exactamente con el ideal caballeresco. Salas Barbadillo, amigo de Cervantes, ofrece en su obra El Caballero Perfecto (1620) una imagen del caballero ideal, que incluiría viajes por Castilla, Nápoles, Flandes, Alemania. 
Tampoco tiene en cuenta las condiciones del medio, como llevar yelmo en julio por la Mancha, ni las costumbres de la sociedad en la que vive. Además, el ejercicio de imitatio debía hacerse según Fox Morcillo, uno de los más insignes humanistas españoles, sin imitar sólo a uno ni imitar todo de uno (Maravall, Antiguos y Modernos 301). Nuestro caballero, aunque tiene un buen conocimiento de las novelas de caballería, tiende a imitar sólo a Amadís: "Quiero, Sancho, que sepas que el famoso Amadís de Gaula fue uno de los más perfectos caballeros andantes. No he dicho bien fue uno: fue él sólo, el primero, el único, el señor de todos cuantos hubo en su tiempo en el mundo" (Cervantes 257). En relación con lo anterior, Vives había establecido la imitación como un aspecto circunscrito al joven en sus años de trabajo formativo, pero no en el viejo ya formado (Maravall, Antiguos y Modernos 304), aspecto que también contradice nuestro protagonista manifiestamente.

La imposibilidad de completar una imitación triunfadora sobre los caballeros que le sirven de modelo, como consecuencia de todas las razones que hemos ido desgranando, devendrá en una deconstrucción como caballero de Don Quijote, intensificada en la Segunda Parte, cuando va adquiriendo conciencia viva de que no sólo no podrá superar a sus modelos, sino que éstos incluso se le escapan de entre las manos como tales. Su derrota en Barcelona, es la derrota de sus modelos, como bien recoge Moner (136): "Désarçonné sur la plage funeste de Barcelone, c'est le vieil idéal de la chevalerie qui bascule avec lui dans la tombe" (136). Paradójicamente, su fracaso como caballero, proveniente de la progresiva disociación entre su discurso de triunfo sobre los antiguos y los hechos de la realidad, propiciará la victoria final sobre sí mismo, la de más prestigio según la filosofía humanista, con la consiguiente toma de conciencia de su identidad. De este modo, será en este vencimiento y en el de su muerte, precedida de la de sus modelos, donde aventaje a éstos: "As Don Quijote slowly abandons or compromises his principle of chivalric imitation...he gains in humanity and shares increasingly in the everyday world of Sancho Panza and the rest of us. This evolutionary process, especially in its protracted final stage, forms a meaningful process of disillusionment and increasing self-knowledge" (Mancing 215). Los sobrepasará en la forma de morir, sosegada y cristiana, imponiéndose sobre ellos desde el momento en que toma un control de su muerte que no tuvo en vida, y que sigue otro patrón muy diferente, el de los libros de buen morir. De este modo, su historia quedará perfecta, apareciendo conclusa, frente a la de la mayoría de los caballeros antiguos sobre los que se produce su victoria ${ }^{16}$, y a los que asimismo superará en fama y en gloria, a unos niveles que ni en su discurso más triunfante hubiese podido imaginar.

Las páginas anteriores han tratado de mostrar cómo Don Quijote hace de la disputa entre antiguos y modernos un aspecto fundamental en la construcción de

16. "Closely related to their pseudo-historicity is a second characteristic of all the Spanish romances of chivalry, their deliberate inconclusiveness" (EISENBERG 127).

ANALES CERVANTINOS, VOL. XXXVII, PP. 191-207, 2005. ISSN: 0569-9878 
su identidad, articulando para ello un mundo a su medida, que no es exactamente ni el indefinido de los libros de caballerías, ni el que le ha tocado vivir. Este último, convertido en el peor posible dentro de su subjetividad, daría a su misión una vertiente providencialista que iría más lejos de la individualista de sus modelos, basada exclusivamente en el deseo de gloria, convirtiendo a la caballería que ejerce en un reducto de la transmisión del progreso humano propuesta por el humanismo. De este modo, se produciría la doble ironía de que lo anquilosado, la caballería, sea presentado en progreso moral, mientras que lo verdaderamente en progreso, el mundo, se describa anquilosado moralmente, además del hecho de que la mejora, el espíritu de novedad y progreso, sea encarnado por un viejo. Para lograr sus objetivos se embarcaría en un proceso de imitación superador de sus modelos, que se bifurcaría en el cuestionamiento de los mismos en tensión con su exaltación, así como en su propio ensalzamiento en función de sus tres atributos caballerescos. Las desfavorables circunstancias de su siglo para el ejercicio de las armas, además de las derivadas de sus errores en el proceso imitativo y de sus propias deficiencias particulares, crearán unas divergencias insalvables entre su discurso emulador y la realidad, que le conducirán a una derrota interior ficticia, pues si hubiese sido caballero de verdad y más valiente que Amadís, nunca su siglo le hubiese permitido igualar sus hazañas. Ésta será, por tanto, sólo aparente, al estar el triunfo además de en la mera aspiración en la victoria sobre si mismo, tras liberarse de las cadenas de la imitatio, y en su posterior muerte, como ámbitos finales donde consigue superar a sus modelos. Su victoria final se verá refrendada por la consecución de los objetivos de fama y gloria tras su muerte ${ }^{17}$, por haber contribuido a mantener viva la llama del ideal humanista, así como por el no menos trascendental hecho de haber encontrado al historiador perfecto capaz de transmitir sus logros a las generaciones posteriores.

\section{BIBLIOGRAFÍA}

Cervantes, Miguel de, El Ingenioso Hidalgo Don Quijote de la Mancha, Barcelona, Planeta, 1980.

Curtius, Ernst R., European Literature and the Latin Middle Ages (trad. de Willard R. Trask), London, Routledge and Kegan, 1953.

Egido, Aurora, "La Memoria y el Quijote", Cervantes: Bulletin of Cervantes Society of America, 11 (1991): 3-45.

EISENBERG, Daniel, Romances of Chivalry in the Spanish Golden Age, Newark, Juan de la Cuesta, 1982.

Foucault, Michel. Las Palabras y las Cosas, Barcelona, Planeta, 1985.

17. Para Edward C. RILEY la ironía máxima del Quijote está en el destino póstumo de haber ganado mayor fama como héroe literario de lo que jamás pudo haber soñado, pero no sólo como triunfador glorioso, sino como prototipo de un héroe nuevo, moderno y democrático (35). 
Lida De Malkiel, María Rosa, La Idea de la Fama en la Edad Media Castellana, México, Fondo de Cultura Económica, 1952.

Mancing, Howard, The Chivalric World of Don Quijote, Columbia, University of Missouri Press, 1982.

Maravall, José Antonio, El Humanismo en las Armas de Don Quijote. Madrid. Instituto de Estudios Políticos, 1948.

-, Utopía y Contrautopía en el Quijote, Santiago, Pico Sacro, 1976.

-, Antiguos y Modernos, Madrid, Alianza, 1986.

Moner, Michel, Cervantes: Deux Themes Majeurs (L'Amour - les Armes et les Lettres), Toulouse, France-Iberie Recherche, 1986.

Presberg, Charles D., "Yo sé quien soy: Don Quixote, Don Diego de Miranda and the Paradox of Self-Knowledge", Cervantes: Bulletin of Cervantes Society of America, 14 (1994): 41-71.

Riley, Edward C.: "La Singularidad de la Fama de Don Quijote". Cervantes: Bulletin of Cervantes Society of America, 22 (2002): 43-70.

RIQUER, Martín de, Vida Caballeresca en la España del Siglo XV, Madrid, Gráficas Marina, 1965

Rodríguez de Montalvo, Garci, Amadís de Gaula, Madrid, Cátedra, 1989.

Russell, Peter E., Temas de la Celestina y Otros Estudios, Barcelona, Ariel, 1978.

\section{Resumen}

El estudio trata de mostrar cómo la disputa entre antiguos y modernos se constituye en un aspecto crucial en la autoconstrucción y en la deconstrucción de la identidad de Don Quijote. Éste, para lograr sus objetivos, se embarca en un proceso de imitación superador de sus modelos que se bifurca en el cuestionamiento de los mismos en tensión con su exaltación, así como en su autoensalzamiento en función de sus mismos atributos caballerescos. Tras analizar las desfavorables circunstancias de su siglo para el ejercicio de las armas, las derivadas de sus errores en el proceso imitativo y de sus propias deficiencias particulares, se ponen de relieve las divergencias insalvables entre su discurso emulador y la realidad, que le conducen a una derrota interior ficticia. Ésta será sólo aparente, al conseguir la mayor victoria, sobre si mismo, tras liberarse de la imitiatio y en su posterior muerte, en la que supera a sus modelos. Su victoria final se verá refrendada por la consecución de sus objetivos de fama y gloria tras la muerte, por haber contribuido a mantener viva la llama humanística y por haber encontrado al historiador perfecto capaz de transmitir sus logros a las generaciones posteriores.

Palabras clave: antiguos y modernos, imitación/imitatio, armas, victoria.

\section{Summary}

This study intends to demonstrate how the dispute between the Classic and Modern thought is constituted in a crucial aspect in the self-construction and deconstruction of Don Quixote's identity, whom in order to attain his goals, embarks on a process of imitation to go beyond his models in order to branch off in challenge of them in tension with their flattery, as well as in his own self-flattery based on his chivalrous attributes. After analyzing the unfavorable circumstances of his century for the exercise of arms, in addition to those derived from their errors in the imitative process and from their own particular deficiencies, the insurmountable divergences between his emulator speech and the 
reality, lead him to a fictitious inner defeat. This will only be apparent, when obtaining the greater victory - self-defeat - after freeing themselves of imitiatio and later in his death, he will surpass his previous models. He will authenticate his final victory by attaining his objectives of fame and glory after his death, by his contributions in maintaining the humanistic flame alive and by having found the perfect historian who will tell his story to later generations.

Key words: Classic and Modern, imitation/imitatio, victory. 